\title{
BMJ
}

\section{Bullous pemphigoid and pemphigus vulgaris-incidence and mortality in the UK: population based cohort study}

\author{
S M Langan, research fellow, ${ }^{1} \mathrm{~L}$ Smeeth, professor of clinical epidemiology, ${ }^{2} \mathrm{R}$ Hubbard, professor of \\ respiratory epidemiology, ${ }^{3} \mathrm{~K}$ M Fleming, research associate, ${ }^{3} \mathrm{C}$ J P Smith, senior research fellow, ${ }^{3}$ \\ J West, clinician scientist ${ }^{3}$
}

${ }^{1}$ Centre of Evidence-based Dermatology, University of Nottingham, Queen's Medical Centre, Nottingham NG7 2UH

${ }^{2}$ Department of Epidemiology and Population Health, Centre for

Population Studies, Non-

Communicable Disease

Epidemiology, London School of

Hygiene and Tropical Medicine,

London

${ }^{3}$ Division of Epidemiology and

Public Health, University of

Nottingham

Correspondence to: S Langan sinead.langan@nottingham.ac.uk

Cite this as: $B M J$ 2008;337:a180 doi:10.1136/bmj.a180

\section{ABSTRACT}

Objective To determine the incidence of and mortality from bullous pemphigoid and pemphigus vulgaris in the United Kingdom.

Design Retrospective historical cohort study.

Setting Computerised medical records from the health improvement network, a large population based UK general practice database.

Participants Patients with pemphigus vulgaris and bullous pemphigoid diagnostic codes and age, sex, and practice matched controls.

Main outcome measures Incidence and mortality compared with the control population by calendar period, age group, sex, geographical region, and degree of social deprivation.

Results 869 people with bullous pemphigoid and 138 people with pemphigus vulgaris were identified. The median age at presentation for bullous pemphigoid was 80 (range 23-102) years, and 534 (61\%) patients were female. The median age at presentation for pemphigus vulgaris was 71 (21-102) years, and 91 (66\%) patients were female. Incidences of bullous pemphigoid and pemphigus vulgaris were 4.3 (95\% confidence interval 4.0 to 4.6 ) and 0.7 (0.6 to 0.8 ) per 100000 person years. The incidence of bullous pemphigoid increased over time; the average yearly increase was $17 \%$ (incidence rate ratio $=1.2,95 \%$ confidence interval 1.1 to 1.2 ). An average yearly increase in incidence of pemphigus vulgaris of $11 \%$ (incidence rate ratio=1.1, 1.0 to 1.2 ) occurred. The risk of death for patients with bullous pemphigoid was twice as great as for controls (adjusted hazard ratio $=2.3,95 \%$ confidence interval 2.0 to 2.7 ).

For pemphigus vulgaris, the risk of death was three times greater than for controls (adjusted hazard ratio=3.3, 2.2 to 5.2).

Conclusions Incidences of bullous pemphigoid and pemphigus vulgaris are increasing. The reasons for in incidence are not clearly understood but have implications for identifying causative factors. are associated with a high risk of death. Previous estimates may have underestimated the risk of death associated with these diseases.

\section{INTRODUCTION}

Little is known about the epidemiology of bullous pemphigoid and pemphigus vulgaris. ${ }^{12}$ Both of these autoimmune disorders, which cause blistering of the skin and mucous membranes, need intensive management by dermatologists in partnership with primary care physicians and other specialties, including ophthalmology and oral medicine, and disease management is often very challenging.

Previous studies of bullous pemphigoid have reported incidences between 0.2 and 3 per 100000 person years; these are higher in older age groups, and some studies report associations with sex..$^{2-4}$ In the United Kingdom, a regional study estimated an incidence of 1.4 per 100000 person years. ${ }^{5}$ Wide variation in mortality is reported, with one year mortality varying between $6 \%$ in the United States and $41 \%$ in France. ${ }^{67}$

In the few hospital based studies of the epidemiology of pemphigus vulgaris, the reported incidence varied between 0.076 and 1.6 per 100000 person years. ${ }^{89}$ Several studies have suggested a higher incidence in women. ${ }^{910}$ No epidemiological data are available from the UK. Before oral corticosteroids were used, this disorder was fatal. ${ }^{11}$ Two hospital based studies report one year mortality of $4.8 \%$ and $54 \%$, with no clear estimate of overall disease specific mortality. ${ }^{12} 13$

The published studies are mainly small and hospital based; thus, although they have an excellent validity, they are unlikely to represent the full spectrum of disease. They are susceptible to selection bias, possibly leading to underestimation of incidence and overestimation of mortality. We carried out a large population based study in people with bullous pemphigoid and pemphigus vulgaris to provide robust data on incidence and demographic data in the UK and to resolve the controversies about mortality from these diseases. This study gives a more general population view of the impact of these diseases.

\section{METHODS}

The health improvement network is a computerised longitudinal general practice database with demographic data similar to the general population. The 


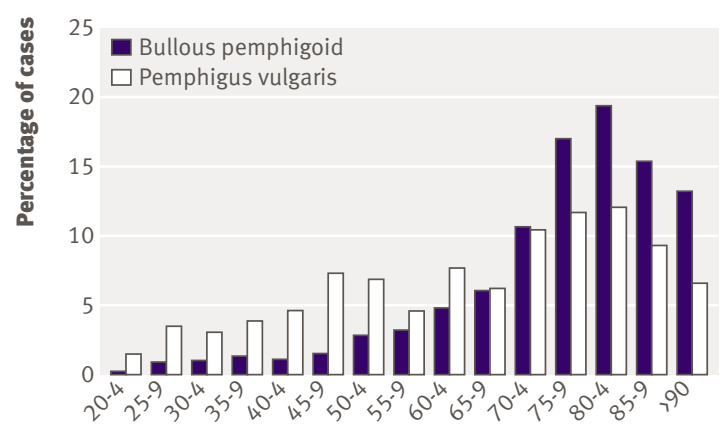

Age category (years)

Fig 1 Age at diagnosis in patients with bullous pemphigoid and pemphigus vulgaris

version we used contained data from 328 general practices that use "In Practice Vision" software. Several studies have confirmed that the health improvement network data are sufficiently accurate for use in epidemiological research. ${ }^{1415}$ The quality of the data has been validated against the general practice research database, a data source for more than 250 peer reviewed publications, and well confirmed disease associations have been replicated. ${ }^{16}$

\section{Study population}

Between 1996 and 2006, we identified all patients with a diagnosis of bullous pemphigoid or pemphigus vulgaris from the health improvement network database. In order to exclude prevalent cases, we imposed a lag period of three months after registration with their general practitioner. This method has been previously validated by Lewis and colleagues to differentiate between incident and prevalent cases of disorders that present acutely. ${ }^{17}$ We selected a control group of up to four controls per case, matched randomly by age, sex, and general practice. Controls also had to be alive and contributing data to the health improvement network database on the date of diagnosis of the matched case. We excluded people aged under 20 years from both cases and controls, as both disorders are rare in this age group and may represent different diseases. We assigned a date of "pseudodiagnosis" to controls, which was the date of diagnosis for the matched case.

\section{Outcomes}

We recorded incident diagnoses and dates of death. The follow-up period began on the date of first diagnosis or the date of "pseudodiagnosis" for controls.

\section{Statistical analysis}

Incidence - We calculated incidences by age, categorised into 10 year age bands; sex; and calendar period. We used multivariate regression to model incidence rate ratios, adjusting for changes in age, sex structure, and calendar period over time. We applied calculated incidences for both diseases to the UK population totals for the years 2001-5 to estimate the number of new cases a year.
Mortality - We identified all deaths in the two case populations and matched controls and used KaplanMeier techniques to calculate one year mortality and five year survival rates. We used Cox regression to compare the mortality of cases and controls, adjusting for age, sex, and calendar period. We used Nelson-Aalen plots to test the proportional hazards assumption.

Office for National Statistics data-We calculated expected numbers of incident cases and deaths for both diseases by applying study rates to the Office for National Statistics population (2001-5) and comparing results with Office for National Statistics data.

Sample size and power calculations - The dataset for this study contained two million person years of data. Assuming a total of 1000 cases, this study would have $90 \%$ statistical power to detect a hazard ratio for death of 2.0 or greater in cases compared with controls, at the $5 \%$ level of significance.

\section{RESULTS}

Our cohort included 869 people with bullous pemphigoid contributing 1993 person years and 3453 matched controls contributing 9765 person years. The median age at first presentation for bullous pemphigoid was 80 (range 23-102) years (fig 1), and 534 (61\%) patients were women. One hundred and thirty eight people with pemphigus vulgaris contributed 380 person years, and 551 matched controls contributed 1763 person years. The median age at first presentation for pemphigus vulgaris was 71 (21-102) years (fig 1), and $91(66 \%)$ patients were women. The median length of follow-up for people with bullous pemphigoid was 1.6 (range 0-9) years, and that for pemphigus vulgaris was 2.0 (0-10.4) years. Losses to follow-up were similar in cases and controls in both diseases (by the end of year 2, bullous pemphigoid cases and controls $34 \%$ lost; pemphigus vulgaris cases 30\% lost, controls 31\% lost) (figs 2 and 3).

\section{Bullous pemphigoid \\ Incidence}

The crude incidence of bullous pemphigoid was 4.28 (95\% confidence interval 4.01 to 4.58 ) per 100000

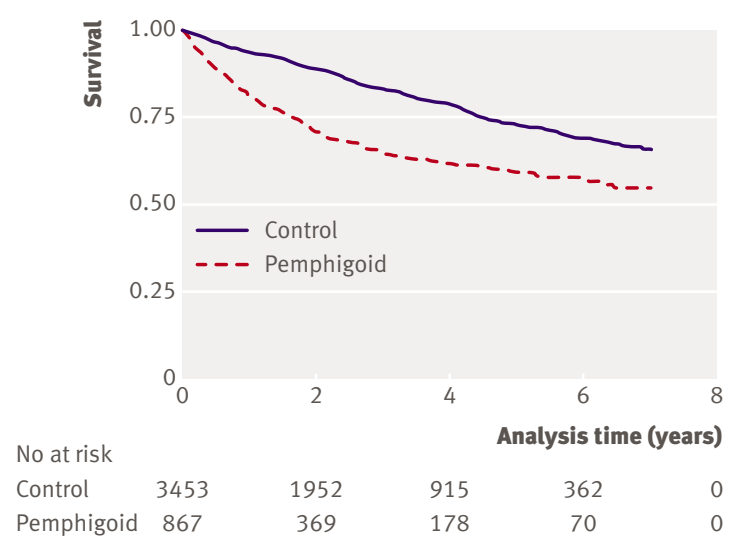

Fig 2 | Kaplan-Meier curve for bullous pemphigoid, showing mortality over time since diagnosis or "pseudodiagnosis" and number of patients remaining in study 
person years. Incidence increased with age (table 1) and in later calendar periods (fig 4). The increased incidence over calendar time persisted after adjustment for age group and sex ( $\mathrm{P}$ for trend $<0.0001)$. The estimated increase in the incidence of bullous pemphigoid per increase in calendar year was 17\% (rate ratio $1.17,95 \%$ confidence interval 1.14 to $1.20 ; \mathrm{P}<0.0001$ ) after adjustment for sex and age group, corresponding to a 4.8 -fold increase in incidence over the 11 year period or a crude increase of 5.2-fold during the study.

As we found no association with Townsend scores and geographical regions, we excluded these from multivariate regression. We found no evidence of effect modification to suggest that this trend was confined to a particular sex, age group, or region. Applying this data to the UK population between 2001 and 2005 gave an average of 2996 (95\% confidence interval 2485 to 3602$)$ new cases a year.

\section{Mortality}

Two hundred and sixty four deaths occurred in the bullous pemphigoid cohort and 604 in the controls, corresponding to an overall crude mortality of 131.99 (95\% confidence interval 116.96 to 148.95 ) per 1000 person years for bullous pemphigoid and 61.86 (57.12 to 66.99) per 1000 person years for controls (table 2). The absolute excess mortality in the bullous pemphigoid cohort was 70 per 1000 person years. The one year mortality for bullous pemphigoid was 19\% (95\% confidence interval $16.2 \%$ to $21.8 \%$ ). These data

Table 1 | Univariate and multivariate analysis of incidence of bullous pemphigoid per 100000 person years, with three month lag period to define incident cases

\begin{tabular}{|c|c|c|c|c|c|c|}
\hline Variable & Person years & Events & $\begin{array}{c}\text { Incidence per } 100000 \\
\text { person years }\end{array}$ & Crude rate ratios & $\begin{array}{l}\text { Mutually adjusted } \\
\text { incidence rate ratios }\end{array}$ & $\begin{array}{l}\text { Likelihood } \\
\text { ratio tests }\end{array}$ \\
\hline Sex: & & & & & & 0.63 \\
\hline Male & 9851101 & 335 & 3.4 (3.1 to 3.8 ) & 1.0 & 1.0 & \\
\hline Female & 10400000 & 534 & 5.1 (4.7 to 5.6$)$ & 1.5 (1.3 to 1.7$)$ & 1.0 (0.9 to 1.2$)$ & \\
\hline Age group (years): & & & & & & $<0.001^{\star}$ \\
\hline$<50$ & 11300542 & 57 & 0.5 (0.4 to 0.7$)$ & 1.0 & 1.0 & \\
\hline $50-59$ & 3128474 & 48 & 1.5 (1.2 to 2.0$)$ & 2.9 (2.0 to 4.3$)$ & 2.9 (2.0 to 4.3$)$ & \\
\hline $60-69$ & 2601248 & 96 & 3.7 (3.0 to 4.5 ) & 7.3 (5.3 to 10.2$)$ & $7.2(5.2$ to 10.0$)$ & \\
\hline $70-74$ & 993535 & 94 & $9.5(7.7$ to 11.6$)$ & 18.6 (13.3 to 25.8$)$ & $18.8(13.5$ to 26.1$)$ & \\
\hline $75-79$ & 878348 & 141 & 16.1 (13.6 to 18.9$)$ & $31.6(32.2$ to 43.0$)$ & $32.0(23.5$ to 43.5$)$ & \\
\hline $80-84$ & 767411 & 174 & 22.7 (19.5 to 26.3$)$ & $44.4(32.9$ to 60.0$)$ & $42.4(31.4$ to 57.3$)$ & \\
\hline $85-89$ & 355633 & 136 & 38.2 (32.3 to 45.2$)$ & 73.6 (53.9 to 100.4$)$ & $73.0(53.5$ to 99.7$)$ & \\
\hline$>90$ & 266833 & 123 & 46.1 (38.6 to 55.0$)$ & 91.4 (66.8 to 125.1$)$ & 86.4 (63.0 to 118.6$)$ & \\
\hline Calendar period: & & & & & & $<0.001^{\star}$ \\
\hline $1996-8$ & 5024756 & 65 & 1.3 (1.0 to 1.6$)$ & 1.0 & 1.0 & \\
\hline $1999-2001$ & 5548756 & 205 & 3.7 (3.2 to 4.2 ) & 2.9 (2.2 to 3.8) & 2.8 (2.1 to 3.7$)$ & \\
\hline $2002-4$ & 5975951 & 351 & 5.9 (5.3 to 6.5$)$ & 4.5 (3.5 to 5.9$)$ & $4.2(3.2$ to 5.5$)$ & \\
\hline $2005-6$ & 3742738 & 248 & 6.6 (5.9 to 7.5$)$ & 5.1 (3.9 to 6.7) & 4.8 (3.6 to 6.3) & \\
\hline Townsend score: & & & & & Not included & \\
\hline 1 & 4701698 & 177 & 3.8 (3.2 to 4.4$)$ & 1.0 & & \\
\hline 2 & 4049263 & 197 & $4.9(4.2$ to 5.6$)$ & 1.3 (1.0 to 1.6$)$ & & \\
\hline 3 & 3909720 & 170 & 4.3 (3.7 to 5.1$)$ & 1.2 (0.9 to 1.4$)$ & & \\
\hline 4 & 3433206 & 156 & 4.5 (3.9 to 5.3$)$ & 1.2 (1.0 to 1.5$)$ & & \\
\hline 5 & 2458831 & 103 & 4.2 (3.5 to 5.1$)$ & 1.1 (0.8 to 1.4$)$ & & \\
\hline Missing & 1739483 & 66 & 3.8 (3.0 to 4.8$)$ & $1.0(0.8$ to 1.3$)$ & & \\
\hline Region: & & & & & Not included & \\
\hline East & 1717944 & 79 & 4.6 (3.7 to 5.7$)$ & 1.0 & & \\
\hline East Midlands & 1020922 & 52 & 5.1 (3.9 to 6.7 ) & 1.1 (0.8 to 1.6$)$ & & \\
\hline London & 2350474 & 76 & $3.2(2.6$ to 4.0$)$ & 0.7 (0.5 to 1.0$)$ & & \\
\hline North east & 573639 & 17 & 3.0 (1.8 to 4.8$)$ & 0.6 (0.4 to 1.1$)$ & & \\
\hline North west & 2322677 & 90 & 3.9 (3.2 to 4.8$)$ & 0.8 (0.6 to 1.1$)$ & & \\
\hline Northern Ireland & 687514 & 29 & 4.2 (2.9 to 6.1$)$ & 0.9 (0.6 to 1.4$)$ & & \\
\hline Scotland & 1168950 & 49 & $4.2(3.2$ to 5.5$)$ & 0.9 (0.6 to 1.3$)$ & & \\
\hline South east & 3863908 & 175 & 4.5 (3.9 to 5.3 ) & $1.0(0.8$ to 1.3$)$ & & \\
\hline South west & 2015823 & 145 & $7.2(6.1$ to 8.5$)$ & 1.6 (1.2 to 2.1$)$ & & \\
\hline Wales & 1329337 & 52 & 3.9 (3.0 to 5.1$)$ & 0.9 (0.6 to 1.2$)$ & & \\
\hline West Midlands & 2024450 & 63 & 3.1 (2.4 to 4.0$)$ & 0.7 (0.5 to 0.9$)$ & & \\
\hline Yorkshire & 1216563 & 42 & 3.5 (2.6 to 4.7 ) & $0.7(0.5$ to 1.1$)$ & & \\
\hline
\end{tabular}




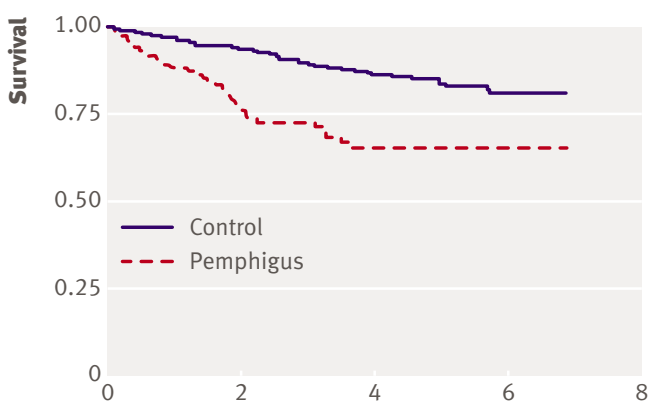

Analysis time (years)

No at risk

Control 551

353

70

164

75

13

Fig 3 | Kaplan-Meier curve for pemphigus vulgaris, showing mortality over time since diagnosis or "pseudodiagnosis" and number of patients remaining in study

correspond to a hazard ratio of 2.11 (95\% confidence interval 1.82 to 2.44). After adjustment for age, sex, and calendar period, this increased to 2.29 (1.98 to 2.65). We found no evidence of effect modification by calendar time, as the hazard ratios comparing disease cohorts with controls for each period were similar (table 3 and fig 2).

\section{Pemphigus vulgaris \\ Incidence}

The crude incidence of pemphigus vulgaris was 0.68 (0.58 to 0.80$)$ per 100000 person years. Incidence was higher in women and in older age groups (fig 1 and table 4). We found evidence of an estimated $11 \%$ increase in incidence per calendar year (incidence rate ratio 1.11 (1.04 to 1.17 ) per year; $\mathrm{P}=0.001$ ) (fig 4$)$. We saw a slight reduction in incidence in the most recent period from 3.5 (1.9 to 6.2) in 2002-4 to 2.4 (1.2 to 4.5 ) in 2005-6 (table 4). Applying these data to the UK population between 2001 and 2005 gave an average of 467 (297 to 643 ) new cases of pemphigus vulgaris a year.

\section{Mortality}

Thirty six deaths occurred in the pemphigus vulgaris cohort and 58 deaths in controls, corresponding to an overall crude mortality of 94.64 (68.268 to 131.205$)$ per 1000 person years for pemphigus vulgaris and 32.89 (25.43 to 42.55 ) per 1000 person years for controls (table 2). The absolute excess mortality in the

Table 2 | Crude and adjusted survival analysis for patients with bullous pemphigoid and pemphigus vulgaris

\begin{tabular}{lcccc} 
& Deaths & Person years & $\begin{array}{c}\text { Crude hazard ratio } \\
(95 \% \mathrm{Cl})\end{array}$ & $\begin{array}{c}\text { Adjusted hazard ratio } \\
(95 \% \mathrm{Cl})\end{array}$ \\
$\begin{array}{l}\text { Bullous pemphigoid } \\
\text { Controls }\end{array}$ & 604 & 9765 & 1.0 & 1.0 \\
\hline Cases & 264 & 1993 & $2.11(1.82$ to 2.44$)$ & $2.29(1.98$ to 2.65) \\
\hline Pemphigus vulgaris & & & 1.0 & 1.0 \\
\hline Controls & 58 & 1763 & $2.82(1.86$ to 4.27) & $3.38(2.21$ to 5.17) \\
\hline Cases & 36 & 380 & &
\end{tabular}

pemphigus vulgaris cohort was 62 per 1000 person years. The one year mortality for pemphigus vulgaris was $12 \%$ ( $8 \%$ to $19 \%)$, and the corresponding hazard ratio was 2.82 (1.86 to 4.27 ). We saw no deaths in cases aged less than 50 years, so we took the 50-59 year age group as the baseline group for multivariate analyses. After adjustment for sex, calendar period, and age group, the hazard ratio for death in cases increased markedly to 3.38 (2.21 to 5.17) (fig 2).

\section{Comparison with Office for National Statistics mortality} data

Applying the mortality data to the UK population data gave 1977 deaths in bullous pemphigoid cases and 221 deaths in pemphigus vulgaris cases (2001-5). These are much higher figures than the 190 and 36 deaths attributed to these diseases in the Office for National Statistics dataset.

\section{DISCUSSION}

We found a substantial increase in the incidence of both bullous pemphigoid and pemphigus vulgaris between 1996 and 2005. This increase was not associated with any reduction in mortality over the calendar periods and is therefore unlikely to be explained by ascertainment bias leading to the diagnosis of less severe cases. Our study therefore suggests that almost 3000 new cases of bullous pemphigoid and 500 of pemphigus vulgaris occur each year. Age and sex adjusted mortality was more than twice as high in people with bullous pemphigoid compared with the general population and three times as high in those with pemphigus vulgaris. These diseases are important causes of death; the Office for National Statistics dataset reports 190 deaths from bullous pemphigoid and 36 deaths from pemphigus vulgaris between 2001 and 2005. The reported mortality for bullous pemphigoid increased from 63 to 88 per 1000 person years between 2001 and 2005, and that for pemphigus vulgaris increased from 13 to 19 per 1000 person years. Applying the mortality data from our study to the Office for National Statistics population gives a much higher estimate of 2198 deaths between both diseases in the UK between 2001 and 2005, although we did not measure the underlying cause of death.

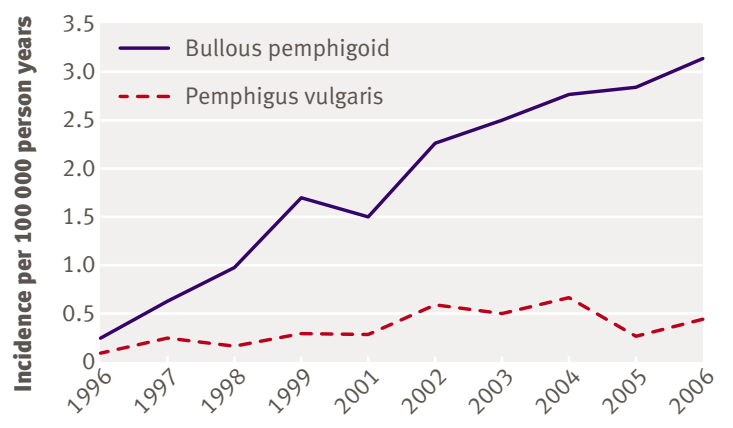

Year

Fig 4 | Age adjusted rates of bullous pemphigoid and pemphigus vulgaris, with direct standardisation to European standard population 
Table $3 \mid$ Hazard rates for death by calendar period comparing bullous pemphigoid and pemphigus vulgaris with controls

Hazard ratio $(95 \% \mathrm{Cl})$

\begin{tabular}{lcc}
\cline { 2 - 3 } Calendar period & Bullous pemphigoid & Pemphigus vulgaris \\
$1996-8$ & $2.15(1.47$ to 3.15$)$ & $2.11(0.66$ to 6.72$)$ \\
\hline $1999-2001$ & $1.72(1.32$ to 2.24$)$ & $2.42(1.13$ to 5.17$)$ \\
\hline $2002-4$ & $2.34(1.88$ to 2.90$)$ & $3.43(1.92$ to 6.11$)$ \\
\hline $2005-6$ & $2.97(1.87$ to 4.72$)$ & $8.75(0.79$ to 96.52$)$ \\
\hline
\end{tabular}

\section{Strengths and weaknesses}

This is a large, population based study, which allows robust estimation of incidence and mortality. This is less susceptible to selection bias than other study designs and allows prospective study of disease trends over time. The size of the dataset gives sufficient power to exclude chance as the basis for the findings. The use of routinely collected data means that we could not validate the diagnoses or assess severity of disease. These diagnoses are made in secondary care, usually with skin biopsies and immunofluorescent techniques to confirm the clinical diagnosis; they are therefore likely to be accurate. Both bullous pemphigoid and pemphigus vulgaris are uncommonly seen in general practice, and general practitioners are highly unlikely to record these diagnoses without referring to secondary or tertiary care. The potentially catastrophic consequences of giving corticosteroids or other immunosuppressants to people with infective causes of blistering mean that appropriate investigations are

Table 4 | Univariate and multivariate analysis of incidence of pemphigus vulgaris per 100000 person years, with three month lag period to define incident cases

\begin{tabular}{|c|c|c|c|c|c|c|}
\hline Variable & Person years & Events & $\begin{array}{c}\text { Incidence per } 100000 \\
\text { person years }\end{array}$ & Crude rate ratios & $\begin{array}{l}\text { Mutually adjusted } \\
\text { incidence rate ratios }\end{array}$ & $\begin{array}{l}\text { Likelihood } \\
\text { ratio tests }\end{array}$ \\
\hline Sex: & & & & & & 0.02 \\
\hline Male & 9851101 & 47 & 0.5 (0.4 to 0.6$)$ & 1.0 & 1.0 & \\
\hline Female & 1040000 & 91 & $0.9(0.7$ to 1.1$)$ & $1.8(1.3$ to 2.6$)$ & 1.5 (1.1 to 2.2$)$ & \\
\hline Age group (years): & & & & & & $<0.001^{\star}$ \\
\hline$<50$ & 11300542 & 34 & 0.3 (0.2 to 0.4$)$ & 1.0 & 1.0 & \\
\hline $50-59$ & 3128474 & 16 & 0.5 (0.3 to 0.8$)$ & 1.8 (1.0 to 3.2$)$ & 1.7 (1.0 to 3.2 ) & \\
\hline $60-69$ & 2601248 & 18 & 0.7 (0.4 to 1.1$)$ & 2.2 (1.2 to 4.0$)$ & 2.2 (1.2 to 4.0$)$ & \\
\hline $70-74$ & 993535 & 11 & 1.1 (0.6 to 2.0$)$ & 3.8 (1.9 to 7.5$)$ & 3.7 (1.9 to 7.4$)$ & \\
\hline $75-79$ & 878348 & 16 & 1.8 (1.1 to 3.0$)$ & 6.2 (3.4 to 11.3$)$ & 6.1 (3.4 to 11.2$)$ & \\
\hline $80-84$ & 767411 & 20 & $2.6(1.7$ to 4.0$)$ & $8.9(5.1$ to 15.6$)$ & $8.2(4.7$ to 14.4$)$ & \\
\hline $85-89$ & 355633 & 13 & 3.7 (2.1 to 6.3$)$ & 12.5 (6.6 to 23.8 ) & 11.4 (6.0 to 21.8 ) & \\
\hline$>90$ & 266833 & 10 & 3.7 (2.0 to 7.0$)$ & 12.8 (6.3 to 26.0$)$ & 11.1 (5.4 to 22.6$)$ & \\
\hline Calendar period: & & & & & & $0.002^{*}$ \\
\hline $1996-8$ & 5024756 & 14 & $0.3(0.2$ to 0.5$)$ & 1.0 & 1.0 & \\
\hline $1999-2001$ & 5548756 & 37 & 0.7 (0.5 to 0.9 ) & 2.4 (1.3 to 4.4$)$ & 2.4 (1.3 to 4.4$)$ & \\
\hline $2002-4$ & 5975951 & 60 & 1.0 (0.8 to 1.3$)$ & $3.6(2.0$ to 6.5$)$ & 3.5 (1.9 to 6.2 ) & \\
\hline $2005-6$ & 3742738 & 27 & 0.7 (0.5 to 1.1$)$ & 2.6 (1.4 to 4.9$)$ & $2.4(1.2$ to 4.5$)$ & \\
\hline Townsend score: & & & & & Not included & \\
\hline 1 & 4701698 & 33 & 0.7 (0.5 to 1.0$)$ & 1.0 & & \\
\hline 2 & 4049263 & 18 & $0.4(0.3$ to 0.7$)$ & 0.6 (0.4 to 1.1$)$ & & \\
\hline 3 & 3909720 & 32 & 0.8 (0.6 to 1.2$)$ & 1.1 (0.7 to 1.8$)$ & & \\
\hline 4 & 3433206 & 20 & $0.6(0.4$ to 0.9$)$ & $0.8(0.5$ to 1.4$)$ & & \\
\hline 5 & 2458831 & 19 & 0.8 (0.5 to 1.2$)$ & 1.2 (0.7 to 2.0$)$ & & \\
\hline Missing & 1739483 & 16 & 0.9 (0.6 to 1.5$)$ & 1.3 (0.7 to 2.4$)$ & & \\
\hline Region: & & & & & Not included & \\
\hline East & 1717944 & 13 & 0.8 (0.4 to 1.3$)$ & 1.0 & & \\
\hline East Midlands & 1020922 & 2 & 0.2 (0.0 to 0.8$)$ & 0.3 (0.1 to 1.1$)$ & & \\
\hline London & 2350474 & 18 & 0.8 (0.5 to 1.2$)$ & $1.0(0.5$ to 2.1$)$ & & \\
\hline North east & 573639 & 5 & 0.9 (0.4 to 2.1$)$ & 1.2 (0.4 to 3.2$)$ & & \\
\hline North west & 2322677 & 9 & $0.4(0.2$ to 0.7$)$ & $0.5(0.2$ to 1.2$)$ & & \\
\hline Northern Ireland & 687514 & 7 & $1.0(0.5$ to 2.1$)$ & 1.3 (0.5 to 3.4$)$ & & \\
\hline Scotland & 1168950 & 3 & 0.3 (0.1 to 0.8$)$ & 0.3 (0.1 to 1.2$)$ & & \\
\hline South east & 3863908 & 30 & 0.8 (0.5 to 1.1$)$ & $1.0(0.5$ to 2.0$)$ & & \\
\hline South west & 2015823 & 27 & 1.3 (0.9 to 2.0$)$ & 1.8 (0.9 to 3.4$)$ & & \\
\hline Wales & 1329337 & 3 & 0.2 (0.1 to 0.7$)$ & 0.3 (0.1 to 1.0$)$ & & \\
\hline West Midlands & 2024450 & 15 & 0.7 (0.4 to 1.2$)$ & $1.0(0.5$ to 2.1$)$ & & \\
\hline Yorkshire & 1216563 & 6 & $0.5(0.2$ to 1.1$)$ & 0.7 (0.2 to 1.7$)$ & & \\
\hline
\end{tabular}




\section{WHAT IS ALREADY KNOWN ON THIS TOPIC}

Little is known about the epidemiology of bullous pemphigoid and pemphigus vulgaris

Bullous pemphigoid is known to be associated with high mortality; mortality of pemphigus vulgaris in western Europe is not known

\section{WHAT THIS STUDY ADDS}

The incidences of bullous pemphigoid and pemphigus vulgaris are increasing, but the reasons for this are not clear

Mortality of bullous pemphigoid is twice that of the general population, and mortality of pemphigus vulgaris is three times as high as in the general population

Previous measures may have underestimated the burden of these diseases, in terms of both incidence and risk of death increased by 39\% between 1998 and 2006. This may have contributed to increased ascertainment but is unlikely to explain completely the increased incidence because of the acute, severe presentations of these disorders.

One year mortality from bullous pemphigoid is lower $(19 \%)$ than previously described in studies from Europe $(25-41 \%)$ but is intermediate between those described in the United States $(11 \%)$ and Europe. ${ }^{35-7} 19$ Non-inclusion of patients in nursing homes is not a likely explanation for this as almost all patients in nursing homes are under the care of general practitioners. Despite recent published literature showing the similar efficacy of potent topical steroids and oral corticosteroids for bullous pemphigoid, oral corticosteroids remain in widespread use and may therefore contribute to high mortality. ${ }^{19}$ One year mortality for pemphigus vulgaris is higher than that described in a recent study of younger cases in Turkey $(4.8 \%)$ but lower than that described in a study from the United States by Ryan and colleagues in 1971 (54\%; mean age of cases not given). ${ }^{12}{ }^{13}$ The designs used in both of these studies are highly susceptible to selection bias, and drawing any robust conclusions from the findings is difficult.

\section{Interpretation and implications}

Our study shows that rates of bullous pemphigoid seem to be increasing over time. Rates of pemphigus vulgaris are increasing to a lesser degree despite the facts that both disorders are more common with increasing age and that the multivariate analysis was adjusted for age. Possible explanations include ascertainment bias, misclassification, and a true increase in incidence. If the last of these is true, further investigation is warranted into the reasons for this, as it may provide further insight into the causes of the disorders. The lack of a socioeconomic gradient and major geographical variation argues against the environment playing an important role in causing the diseases.

Our study has shown high mortality associated with these diseases; rates were twice that in the general population in patients with bullous pemphigoid and three times as high as in the general population in those with pemphigus vulgaris. With the increasing age of our population, the morbidity and mortality from these diseases will increase. Previous measures have underestimated the burden of these diseases, in terms of both incidence and risk of death.

Contributors: SML, RH, LS, and JW were involved in the conception of the research question, planning the study, and applying for ethical approval. $\mathrm{RH}, \mathrm{LS}$, and JW were supervisors of the initial study, which was completed by SML as part of an MSc project at the London School of Hygiene and Tropical Medicine. CJPS extracted the data from the health improvement network database and assisted with data management and guidance on the use of the database. Further data management was by SML, KMF, and JW. SML, KMF, and JW were involved in analysing the data, KMF and JW in a teaching and supervisory capacity. SML drafted the manuscript, which was reviewed by all authors. SML is the guarantor.

Funding: SML is funded by a grant from the BUPA Foundation. LS is supported by a Wellcome Trust senior research fellowship in clinical science. JW is supported by a Department of Health clinician scientist fellowship, and KMF is also funded from that fellowship. 
Competing interests: None declared.

Ethical approval: Nottingham research ethics committee.

Provenance and peer review: Not commissioned; externally peer reviewed.

1 Naldi L, Bertoni M, Cainelli T. Feasibility of a registry of pemphigus in Italy: two years experience. Int J Dermatol 1993;32:424-7.

2 Adam BA. Bullous diseases in Malaysia: epidemiology and natural history. Int J Dermatol 1992;31:42-5.

3 Garcia-Doval I, Mayo E, Nogueira Farina J, Cruces MJ. Bullous pemphigoid triggered by influenza vaccination? Ecological study in Galicia, Spain. Br J Dermatol 2006;155:820-3.

4 Jung M, Kippes W, Messer G, Zillikens D, Rzany B. Increased risk of bullous pemphigoid in male and very old patients: a populationbased study on incidence. J Am Acad Dermatol 1999;41:266-8.

5 Gudi VS, White MI, Cruickshank N, Herriot R, Edwards SL, Nimmo F, et al. Annual incidence and mortality of bullous pemphigoid in the Grampian region of north-east Scotland. Br J Dermatol 2005;153:424-7.

6 Colbert RL, Allen DM, Eastwood D, Fairley JA. Mortality rate of bullous pemphigoid in a US medical center. J Invest Dermatol 2004;122:1091-5.

7 Roujeau JC, Lok C, Bastuji-Garin S, Mhalla S, Enginger V, Bernard P. High risk of death in elderly patients with extensive bullous pemphigoid. Arch Dermatol 1998;134:465-9.

8 Hietanen J, Salo OP. Pemphigus: an epidemiological study of patients treated in Finnish hospitals between 1969 and 1978. Acta Derm Venereol 1982;62:491-6.

9 Pisanti S, Sharav Y, Kaufman E, Posner LN. Pemphigus vulgaris: incidence in Jews of different ethnic groups, according to age, sex, and initial lesion. Oral Surg Oral Med Oral Pathol 1974;38:382-7.

10 Salmanpour R, Shahkar H, Namazi MR, Rahman-Shenas MR. Epidemiology of pemphigus in south-western Iran: a 10-year retrospective study (1991-2000). Int J Dermatol 2006;45:103-5.

11 Gellis S, Glass FA. Pemphigus: a survey of one hundred and seventy patients admitted to Bellevue Hospital from 1911 to 1941. Arch Dermatol Syphiol 1941;44.
12 Uzun S, Durdu M, Akman A, Gunasti S, Uslular C, Memisoglu HR, et al. Pemphigus in the Mediterranean region of Turkey: a study of 148 cases. Int J Dermatol 2006;45:523-8.

13 Ryan JG. Pemphigus: a 20-year survey of experience with 70 cases. Arch Dermatol 1971;104:14-20.

14 Lewis JD, Schinnar R, Bilker WB, Wang X, Strom BL. Validation studies of the health improvement network (THIN) database for pharmacoepidemiology research. Pharmacoepidemiol Drug Saf 2007;16:393-401.

15 Bath-Hextall F, Leonardi-Bee J, Smith C, Meal A, Hubbard R. Trends in incidence of skin basal cell carcinoma: additional evidence from a UK primary care database study. Int J Cancer 2007;121:2105-8.

16 Lewis JD, Schinnar R, Bilker WB, Wang X, Strom BL. Validation studies of the health improvement network (THIN) database for pharmacoepidemiology research. Pharmacoepidemiol Drug Saf 2006;16:393-401.

17 Lewis JD, Bilker WB, Weinstein RB, Strom BL. The relationship between time since registration and measured incidence rates in the general practice research database. Pharmacoepidemiol Drug Saf 2005;14:443-51.

18 Lewis JD, Brensinger C, Bilker WB, Strom BL. Validity and completeness of the general practice research database for studies of inflammatory bowel disease. Pharmacoepidemiol Drug Saf 2002;11:211-8.

19 Joly P, Roujeau JC, Benichou J, Picard C, Dreno B, Delaporte E, et al. A comparison of oral and topical corticosteroids in patients with bullous pemphigoid. N Engl J Med 2002;346:321-7.

20 Joly P, Benichou J, Saiag P, Bernard P, Roujeau JC. Response to: mortality rate of bullous pemphigoid in a US medical center. I Invest Dermatol 2005;124:664-5.

21 V'Ickova-Laskoska MT, Laskoski DS, Kamberova S, Caca-Biljanovska N, Volckova N. Epidemiology of pemphigus in Macedonia: a 15-year retrospective study (1990-2004). Int J Dermatol 2007;46:253-8.

Accepted: 7 May 2008 